\title{
Refractory Anaplastic Ganglioglioma
}

National Cancer Institute

\section{Source}

National Cancer Institute. Refractory Anaplastic Ganglioglioma. NCI Thesaurus. Code C160915.

Anaplastic gang liog lioma that is resistant to treatment. 